\title{
Mortality and Thromboembolic Events in Hypercoagulable States from Rotational Thromboelastography (ROTEM) in Patients Who Undergo Coronary Bypass Surgery
}

\author{
Sira Laohathai1, Piya Samankatiwat ${ }^{2 *}$ \\ ${ }^{1}$ Cardio Thoracic Surgery Unit, Department of Surgery, Faculty of Medicine Vajira Hospital, Navamindradhiraj University, \\ Bangkok, Thailand \\ ${ }^{2}$ Department of Cardiovascular Thoracic Surgery, Mahidol University Ramathibodi Hospital, Bangkok, Thailand \\ Email: *sira_1@hotmail.com
}

How to cite this paper: Laohathai, S. and Samankatiwat, P. (2019) Mortality and Thromboembolic Events in Hypercoagulable States from Rotational Thromboelastography (ROTEM) in Patients Who Undergo Coronary Bypass Surgery. World Journal of Cardiovascular Surgery, 9, 133-142. https://doi.org/10.4236/wjcs.2019.910015

Received: September 8, 2019

Accepted: September 26, 2019

Published: September 29, 2019

Copyright $\odot 2019$ by author(s) and Scientific Research Publishing Inc. This work is licensed under the Creative Commons Attribution International License (CC BY 4.0).

http://creativecommons.org/licenses/by/4.0/

\begin{abstract}
Purpose: This study is to identify the prevalence of preoperative hypercoagulability in Thailand high-risk population assessed by Rotational thromboelastography (ROTEM) and test hypothesis that the pre-surgical ROTEM statuses are related to MACCE at 1, 12, 60 months after coronary bypass graft surgery (CABG). Method: This is a prospective cohort in consecutive patients who underwent on-pump CABG between 2013-2015. Blood samplings were collected and analyzed using ROTEM preoperatively. Hypercoagulable state was defined as any clotting time (CT) or clot formation time (CFT) below the lower normal limit or amplitude $10 \mathrm{~min}$ after CT (A10), Maximum clot firmness (MCF) in ROTEM measurement is above the upper normal limit of EXTEM, INTEM and FIBTEM. Results: $43 \%$ of CABG patients who were diagnosed as hypercoagulability state assessed by ROTEM. Mortality rate was slightly higher in hypercoagulable patients without statistical significance ( $9 \%$ vs $5.1 \% ; \mathrm{P}=0.461)$. However, overall combined uneventful rate was significantly increased in hypercoagulable patients in 5 years follow-up (27.2\% vs $8.6 \% ; \mathrm{P}=0.012$ ). In univariate analysis, ROTEM hypercoagulability is associated major adverse cardiovascular and cerebral event (MACCE) in 5 -years follow up [OR $(95 \%$ CI $)=3.975$ (1.28 - 12.32); P = 0.017]. Conclusion: Hypercoagulable patients were identified 43 percent of patients associated with combine uneventful in 5 years follow-up. ROTEM could be applied as a useful tool in the prediction of outcome after CABG surgery.
\end{abstract}


Keywords

Hypercoagulable Stage, CABG, ROTEM

\section{Introduction}

The incidence of coronary artery disease has become significantly increasing during the last few decades. This disease is usually managed either by coronary artery intervention or surgery depending on the severity of coronary disease. Outcomes after coronary bypass surgery (CABG) could be affected by pre-surgical patient risk profile, surgical technique and post-surgical medical. Recently, thromboelastography (TEG) has been introduced in cardiac surgery as a tool for detecting pre-operative hemostatic profile, predicting post-operative bleeding or thromboembolic event and even an outcome after surgery [1]-[7]. Many studies have demonstrated a higher prevalence of hypercoagulability in cardiac surgical patients than in the healthy population [8]. Those patients that hypercoagulable state was assessed by TEG, were associated with an increased risk of post-operative non-cardiac and cardiac surgery complication [2] [9] [10] and especially in postoperative thromboembolic event complications [4] [11].

The aim of this study is to assess the prevalence of Rotational thromboelastography $\left(\right.$ ROTEM $\left.^{\bowtie}\right)$-hypercoagulability in CABG patients and test the hypothesis that mortality rate and thromboembolic event are related to ROTEM hypercoagulability patients in early and mid-term outcome.

\section{Method}

The study design was a prospective cohort from consecutive patients undergoing on-pump CABG procedure in Ramathibodi Hospital, Mahidol University between 2013 and 2015. Preoperative blood sampling was routinely collected at the day before surgery. Our inclusion criteria were age $>18$ years old and only perform in on-pump CABG surgery. Our exclusion was CABG with concomitant surgery, continuing clopidogrel preoperatively or could not obtain the blood sampling. Our data were collected prospectively and all patients were followed every 1 to 3 months in our cardiovascular surgery clinic up until 5-year follow up. All patients gave informed consent upon admission and the local ethics committee approved the study (Protocol number: 10-61-08).

Blood sampling and thromboelastography were analyzed by Rotational thromboelastography (ROTEM ${ }^{\circledR}$ ) (TEM International GmbH, Munich, Germany).

The mechanism of ROTEM was assessed a clot formation/dissolution kinetics and strength by measuring and displaying the amount of a continuously applied rotational force that is transmitted to an electromechanical transduction system by developing clot. In system, a cylindrical cup containing a $340 \mu \mathrm{l}$ whole blood sample oscillates through $4^{\circ} 45^{\prime}$ every $5 \mathrm{sec}$ and a pin on a torsion wire is suspended in the blood. As the viscoelastic strength of the clot increases, more rota- 
tion is transmitted to the torsion wire and is detected by an electromagnetic transducer [12].

Hemostatic profile from ROTEM that reflect to hyper coagulability were Amplitude 10 min after clotting time (A10), Amplitude 20 min after clotting time (A20), Maximum clot firmness (MCF) and alpha angle [13]. Our Definition of hypercoagulability were defined as if any clotting time (CT), clot formation time (CFT) are below the normal limit or Alpha angle, A10 and MCF are above the upper normal limit in either of each group (EXTEM, INTEM and FIBTEM) base on range of worldwide population [14].

\subsection{Surgical Technique}

All CABG procedures were performed through median sternotomy according to our routine clinical practice. One hundred and two patients were undergoing on-pump CABG using cardiopulmonary bypass and extracorporeal circulation (ECC). All patients on ECC were routinely heparinized to maintain an activated clotting time of $>480$ seconds, and this was reversed with protamine-sulphate (1:1) after finalization of ECC. All patients on ECC received a total dose of $4 \mathrm{~g}$ tranexamic acid during surgery. The number, type (arterial or vein) and coronary anastomosis of bypass grafts in each patient were decided by the operating surgeon, based on clinical patient data in addition to the pre-surgical invasive coronary angiography.

\subsection{Definition Term and Outcome}

Dyslipidemia, defined as elevated total or low-density lipoprotein (LDL) cholesterol levels, or low levels of high-density lipoprotein (HDL) cholesterol. End stage renal disease defined as a presence of renal function with estimated GFR < $15 \mathrm{~mL} / \mathrm{min}$. Peripheral arterial disease defined as patients who have the ankle-brachial index (ABI) which less than 0.9 [15] [16].

Major adverse cardiovascular and cerebral events (MACCE) defined as all-cause mortality; thrombotic vascular events, acute myocardial infarction and stroke were recorded. In the immediate post-surgical period acute myocardial infarction was defined as creatinine kinase MB levels $>80 \mathrm{U} / \mathrm{l}$. After discharge acute myocardial infarction was defined by two out of three of the following: acute chest pain, signs of a new acute myocardial infarction on the electrocardiogram or elevation of relevant biomarkers. Stroke was defined as neurological deficits lasting for more than 24 hours.

\subsection{Preoperative Antithrombotic Therapy}

Clopidogrel were routinely discontinued 5 days before surgery. In acute coronary syndrome patients who received urgency operation, Clexane (enoxaparin, a low-molecular-weight heparin (LMWH)) $40 \mathrm{mg}$ was administered subcutaneously twice a day and stopped 12 hours before surgery. For post-operative surgery, all patients were received an aspirin 75 - $162 \mathrm{mg}$ orally within $6-24 \mathrm{~h}$ after surgery. The dosage of aspirin was depended on operating surgeon and if clopidogrel was 
administered after surgery, then it was usually started on the second postoperative day.

\subsection{Statistical Analysis}

For categorical variables, Chi-square $\left(\chi^{2}\right)$ tests or Fisher's exact test were used as appropriate. For continuous variables, analysis was performed with the twosample t-test, after ensuring normal distribution of the data. Data with no normal distribution were analyzed by Wilcoxon's rank-sum test. Univariate and multivariate logistic regression analyses were performed to identify patient characteristics associated with MACCE at 30-day and 5-year follow-up. Continuous variables are presented as mean \pm standard deviation (SD) unless otherwise noted. $\mathrm{P}$-values $<0.05$ were considered statistically significant. In tables, all P-values $>0.10$ are denoted non-significant. All statistical analyses were performed using PASW (SPSS) statistical software v.18.0 (SPSS, Inc., Chicago, IL, USA).

\section{Result}

777 patients were underwent coronary bypass surgery in Ramathibodi Hospital from 2013 to 2015. However, there were 675 cases could not be included in this study due to operation technique (i.e. off-pump, on-pump beating heart surgery or combined with other cardiac surgery) or could not obtain the blood sample before operation or loss follow up during the period.

We found out that $43 \%$ of patients in the study demonstrate hypercoagulability state from ROTEM measurement. In basic characteristic profile, there were no difference in age, smoking history, NYHA, underlying disease, Euroscore or urgency condition except female gender with predominant in hypercoagulable patients $(43.2 \%$ vs $24.1 \% ; \mathrm{P}=0.034$ in Table 1$)$. In laboratory data were also showed similarly in both groups except the number of platelet $(\mathrm{P}=0.03$ in Table 2). For peri-operative data, there were no difference in cardiopulmonary bypass time, aortic clamp time, number of conduits and type of conduits (Table 3).

In post-operative in 30 days, both mortality and MACCE event rate were slightly increased in hypercoagulable patients. However, the statistical were not showed significant $(2.3 \%$ vs $1.7 \% ; \mathrm{P}=0.845$ and $9.1 \%$ vs $1.7 \% ; \mathrm{P}=0.163$, respectively). Causes of mortality rate within 30 days were acute myocardial infarction with cardiogenic shock and uncontrolled septic shock (Table 4). In follow up period, there was still no statistical difference in term of overall survival (Figure 1). However, an incidence of MACCE in hypercoagulability group was dramatically increasing with statistically significant $(27.2 \%$ vs $8.6 \%$; $=0.012)$ (Table 5$)$.

From univariate and multivariate logistic progression, female gender and number of platelets were only two factors that associated with ROTEM hypercoagulability. Moreover, ROTEM hypercoagulable state was a factor that associates with MACCE within 5 years follow up [OR $(95 \% \mathrm{CI})=3.975(1.28-12.32) ; \mathrm{P}=$ 0.017] (Table 6 and Table 7). 


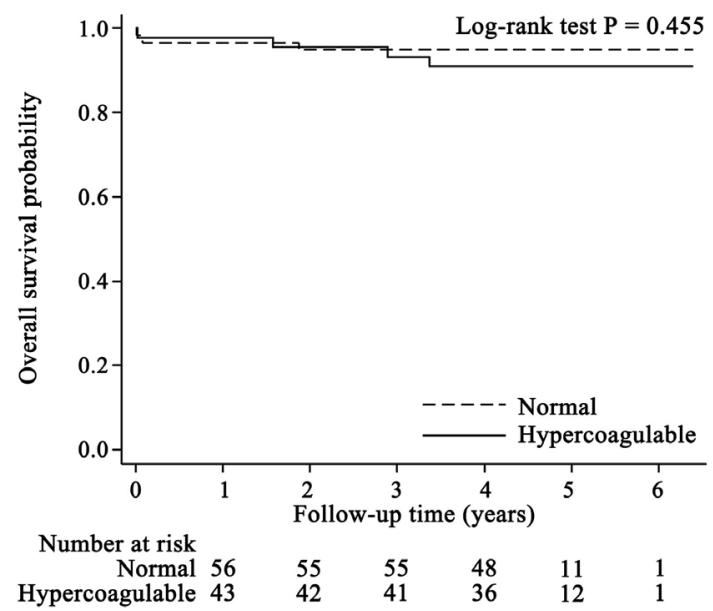

Figure 1. Overall survival between hypercoagulable and normal patients.

Table 1. Patient demographic data.

\begin{tabular}{|c|c|c|c|}
\hline Characteristic data & Hypercoagulable $(\mathrm{N}=44)$ & Normal $(\mathrm{N}=58)$ & P-value \\
\hline Age (year), mean (SD) & $63.0(10.0)$ & $65(8.1)$ & 0.271 \\
\hline BMI $\left(\mathrm{kg} / \mathrm{m}^{2}\right), \mathrm{SD}$ & $24.14(6.8)$ & $24.21(3.3)$ & 0.289 \\
\hline \multicolumn{4}{|l|}{ Sex, n (\%) } \\
\hline Male & $25(56.8)$ & $44(75.9)$ & \multirow[t]{2}{*}{0.034} \\
\hline female & $19(43.2)$ & $14(24.1)$ & \\
\hline \multicolumn{4}{|l|}{ NYHA, n (\%) } \\
\hline 1 & $13(29.5)$ & $18(31.0)$ & \multirow{4}{*}{0.616} \\
\hline 2 & $23(52.2)$ & $33(56.8)$ & \\
\hline 3 & $5(11.4)$ & $6(10.3)$ & \\
\hline 4 & $3(6.9)$ & $1(1.9)$ & \\
\hline \multicolumn{4}{|l|}{ Smoke, n (\%) } \\
\hline Non smoker & $26(59.1)$ & $28(48.2)$ & \multirow{3}{*}{0.287} \\
\hline Ex-smoker & $6(13.6)$ & $5(8.6)$ & \\
\hline Active smoker & $12(27.3)$ & $23(39.6)$ & \\
\hline \multicolumn{4}{|l|}{ Underlying } \\
\hline Diabetes, n (\%) & $23(52)$ & $20(34)$ & 0.055 \\
\hline Diabetes on insulin, n (\%) & $9(20.4)$ & $8(13.8)$ & 0.265 \\
\hline Hypertension, n (\%) & $40(90.9)$ & $50(86.2)$ & 0.342 \\
\hline ESRD, n (\%) & $5(11.3)$ & $5(8.6)$ & 0.446 \\
\hline COPD, n (\%) & $1(2.3)$ & $1(1.7)$ & 0.679 \\
\hline Dyslipidemia, n (\%) & $34(77.2)$ & $37(63.7)$ & 0.274 \\
\hline Autoimmune, $\mathrm{n}(\%)$ & 0 & $1(1.7)$ & 0.569 \\
\hline PAD, n (\%) & $2(4.5)$ & $4(6.9)$ & 0.478 \\
\hline Stroke, n (\%) & $7(15.9)$ & $4(6.9)$ & 0.129 \\
\hline Cancer, n (\%) & $1(2.3)$ & $1(1.7)$ & 0.679 \\
\hline Atrial fibrillation, n (\%) & 0 & $3(6.8)$ & 0.180 \\
\hline Post PCI, n (\%) & $3(6.8)$ & $6(10.3)$ & 0.400 \\
\hline \multicolumn{4}{|l|}{ LVEF } \\
\hline$<30 \%$ & $2(4.5)$ & $6(10)$ & \multirow{3}{*}{0.213} \\
\hline $30 \%-50 \%$ & $25(56)$ & $23(39)$ & \\
\hline$>50 \%$ & $17(38)$ & $29(50)$ & \\
\hline Euroscore, mean (SD) & $1.70(1.37)$ & $1.57(2.21)$ & 0.733 \\
\hline Urgency (\%) & $8(18.1)$ & $7(12)$ & 0.279 \\
\hline
\end{tabular}

BMI, body mass index; COPD, chronic obstructive pulmonary disease; NYHA, New York Heart Association; PCI, percutaneous coronary intervention. 
Table 2. Laboratory data.

\begin{tabular}{cccc}
\hline Laboratory data & Hypercoagulable (N = 44) & Normal $(\mathbf{N}=\mathbf{5 8})$ & P-value \\
\hline Platelet $\left(10^{9} / \mathrm{L}\right)$, mean (SD) & $265(62.2)$ & $232.4(61)$ & 0.010 \\
APTT (sec), SD & $25.6(4.5)$ & $26.3(4.0)$ & 0.346 \\
INR (SD) & $1.0(0.1)$ & $1.0(0.2)$ & 0.152 \\
Creatinine (mg/dL), mean (SD) & $1.0(0.3)$ & $1.0(0.3)$ & 0.802 \\
Hb (g/dL), mean (SD) & $11.8(1.7)$ & $12.5(1.6)$ & 0.046 \\
ALT (U/L), mean (SD) & $37.6(26.9)$ & $40.2(21.4)$ & 0.590 \\
\hline
\end{tabular}

APTT, activated partial thrombin time; $\mathrm{Hb}$, hemoglobin; INR, international normalized ratio; ALT, alanine aminotransferase.

Table 3. Operative data.

\begin{tabular}{cccc}
\hline & Hypercoagulable (N = 44) & Normal (N = 58) & P-value \\
\hline CPB time (mins), SD & $134.7(26.5)$ & $131.5(32.2)$ & 0.591 \\
\hline Aortic clamp time (mins), SD & $109.8(21.4)$ & $104.0(26.2)$ & 0.236 \\
\hline Conduit & & & \\
Number of conduits, SD & $3.77(0.9)$ & $3.88(0.7)$ & 0.531 \\
IMA, n (\%) & $34(77.3)$ & $42(72.4)$ & 0.531 \\
Radial artery, n (\%) & $4(2)$ & $6(10.3)$ & 0.373 \\
SVG, n (\%) & $44(100)$ & $44(100)$ & 0.554 \\
\hline
\end{tabular}

$\mathrm{CPB}$, cardiopulmonary bypass; IMA, internal mammary artery; SVG, saphenous vein graft.

Table 4. Postoperative data.

\begin{tabular}{cccc}
\hline & Hypercoagulable (N = 44) & Normal (N = 58) & P-value \\
\hline Post-operative AF, n (\%) & $10(22.7)$ & $19(32.7)$ & 0.187 \\
\hline Re-operative, n (\%) & $1(2.3)$ & $3(5.2)$ & 0.419 \\
\hline Mortality rate 30 days, n (\%) & $1(2.3)$ & $1(1.7)$ & 0.845 \\
\hline Post-op complication, n (\%) & & 0 & 0.184 \\
Stroke & $2(4.5)$ & 0 & 0.431 \\
MI & $1(2.3)$ & 0 & 0.431 \\
\hline Thromboembolic events & $1(2.3)$ & $1(1.7)$ & 0.163 \\
\hline MACCE within 30 days, n (\%) & $4(9.1)$ & &
\end{tabular}

AF, atrial fibrillation; MACCE, major adverse cardiocerebral events; MI, myocardial infarction.

Table 5. Follow 5 year data.

\begin{tabular}{cccc}
\hline & Hypercoagulable (N = 44) & Normal (N = 58) & P-value \\
\hline Mortality rate in 5 year, n (\%) & $4(9.1)$ & $3(5.2)$ & 0.461 \\
\hline Complication in 5 year, n (\%) & & & \\
Stroke & $5(11.4)$ & $3(5.2)$ & 0.286 \\
MI & $3(6.8)$ & $1(1.7)$ & 0.313 \\
Thromboembolic events & $5(11.4)$ & $2(3.6)$ & 0.234 \\
\hline MACCE in 5 year, n (\%) & $12(27.2)$ & $5(8.6)$ & 0.012
\end{tabular}

MACCE, major adverse cardiocerebral events; MI, myocardial infarction.

Table 6. Univariate and multivariate logistic regression analysis of variables associated with ROTEM-hypercoagulability.

\begin{tabular}{ccccc}
\hline Risk Factor & Univariate & P-value & Multivariate & P-value \\
\hline Female gender & $2.389(1.024-5.572)$ & 0.044 & $2.416(1.002-5.828)$ & 0.050 \\
platelets & $1.009(1.002-1.016)$ & 0.013 & $1.009(1.002-1.016)$ & 0.014 \\
\hline
\end{tabular}


Table 7. Univariate analysis of variables associated MACCE in 5 years follow-up.

\begin{tabular}{ccc}
\hline Risk Factor & Univariate & P-value \\
\hline ROTEM hypercoagulable state & $3.975(1.28-12.32)$ & 0.017 \\
\hline
\end{tabular}

\section{Discussion}

We attempt to demonstrate the prevalence of hypercoagulability of patients undergoing CABG in Thailand. We found out that $43 \%$ of CABG patients were hypercoagulability which was similar to other studies. [17] [18] S. Rafiq et al. [17] also reported that $43 \%$ of their CABG patients were TEG-hypercoagulability. Moreover, this study also identified that female gender is a risk factor of ROTEM hypercoagulability which related to several studies [19] [20] [21]. Roeloffzen et al. and Theusinger et al. were reported that female factor could increase risk of hypercoagulability in healthy middle-aged individuals [19] [20] [21].

In post-operative, our data showed that all 30 days-MACCE events (MI, stroke and all-cause mortality) were slightly increased in ROTEM hypercoagulable patients but 5-years follow up were statistically significant which are concordant as many studies. Zacho and their colleagues demonstrated that patients who were MA $>69$ define as TEG-hypercoagulable is associated with an increased risk of post-surgical thrombo-embolic events but this was not reaching statistical significance. Moreover, they did not find any association between coronary bypass graft failure and thrombelastographic status [11].

Antiplatelet therapy has been well known as an important factor to prevent recurrent ischemic events or graft thrombosis. The efficacy of aspirin is well known as the first line drug for post CABG patients. Currently, clopidogrel which mechanism is an inhibitor of the platelet adenosine diphosphate (ADP) receptor, has been shown a benefit of reducing platelet-mediated thrombotic events especially in off-pump CABG surgery [22] [23]. In hypercoagulability CABG patient, Rafiq believes that the mechanism of hypercoagulability could be caused by hyper aggregation of platelets. In order to prove this theory, they continue to study the phase 2 project (the TEG-CABG trial) between patients who receive aspirin with clopidogrel and aspirin alone in hypercoagulable patients as a randomized control trial. However, their result has not been reported yet [24].

On the contrary, the usage of anti-coagulant agent was seldom used in post CABG. Thao et al. report a randomized control trial among warfarin plus placebo vs aspirin plus placebo vs warfarin plus aspirin in post coronary bypass surgery. They found that adding anti-coagulant therapy or combine two drugs were not gain a benefit than aspirin alone [25] [26]. A meta-analysis by Henderson and his colleagues that was also suggested a little benefit of anti-coagulant agent in post CABG [27].

In this study we have found that A10, A20 and MCF are dramatically increased among EXTEM, INTEM and FIBTEM. Both of their parameters also reflect hypercoagulability pathways. As a result of this, we may be believed that a dual anti-platelet may take a vital role in post ROTEM hypercoagulable on-pump 
CABG patients. There are still no guidelines or study from ECS/EACTS/AHA support an anti-coagulable in addition to aspirin or anti-dual platelet after on-pump CABG patients [26] [28].

In conclusion, the result of this study demonstrates that ROTEM-hypercoagulable patients are at higher risk of MACCE after surgery. Further studies are required to investigate the relationship between hypercoagulability and thromboembolic risk postoperatively in short and long term, and whether this risk can be minimized by a dual anti-platelets therapy.

As a result of our study, a hemostatic profile that was evaluated by ROTEM may potentially become a powerful tool to predict the outcome after the postoperative coronary artery bypass surgery.

\section{Limitation}

Besides the limitations of the number of patients in this study, we did not examine aspirin pre-operatively, postoperative infections, acute renal failure, blood transfusions which could associated with risks for myocardial infarction, stroke and death. We also did not focus in on-pump beating or off-pump surgery due to several studies had shown that their procedure can cause hypercoagulable state [22] [23]. We still need a randomized clinical trials (RCTs) are needed to evaluate whether intensified a dual anti-platelet therapy after surgery would reduce all MACCE and mortality in hypercoagulable patients.

\section{Consent}

All authors read and approved the final manuscript.

\section{Conflicts of Interest}

The authors declare no conflicts of interest regarding the publication of this paper.

\section{References}

[1] Gozdzik, W., Adamik, B., Wysoczanski, G., Gozdzik, A., Rachwalik, M., Skalec, T., et al. (2017) Preoperative Thromboelastometry for the Prediction of Increased Chest Tube Output in Cardiac Surgery: A Retrospective Study. Medicine (Baltimore), 96, e7669. https://doi.org/10.1097/MD.0000000000007669

[2] Gurbel, P.A., Bliden, K.P., Guyer, K., Cho, P.W., Zaman, K.A., Kreutz, R.P., et al. (2005) Platelet Reactivity in Patients and Recurrent Events Post-Stenting: Results of the Prepare Post-Stenting Study. Journal of the American College of Cardiology, 46, 1820-1826. https://doi.org/10.1016/j.jacc.2005.07.041

[3] Kim, E., Shim, H.S., Kim, W.H., Lee, S.Y., Park, S.K., Yang, J.H., et al. (2016) Predictive Value of Intraoperative Thromboelastometry for the Risk of Perioperative Excessive Blood Loss in Infants and Children Undergoing Congenital Cardiac Surgery: A Retrospective Analysis. Journal of Cardiothoracic and Vascular Anesthesia, 30, 1172-1178. https://doi.org/10.1053/j.jvca.2016.03.132

[4] McCrath, D.J., Cerboni, E., Frumento, R.J., Hirsh, A.L. and Bennett-Guerrero, E. (2005) Thromboelastography Maximum Amplitude Predicts Postoperative Throm- 
botic Complications Including Myocardial Infarction. Anesthesia \& Analgesia, 100, 1576-1583. https://doi.org/10.1213/01.ANE.0000155290.86795.12

[5] Soh, S., Kwak, Y.L., Song, J.W., Yoo, K.J., Kim, H.J. and Shim, J.K. (2017) Rotational Thromboelastometry Predicts Increased Bleeding after Off-Pump Coronary Bypass Surgery. The Annals of Thoracic Surgery, 104, 1318-1324.

https://doi.org/10.1016/j.athoracsur.2017.02.046

[6] Wikkelso, A., Wetterslev, J., Moller, A.M. and Afshari, A. (2017) Thromboelastography (TEG) or Rotational Thromboelastometry (ROTEM) to Monitor Haemostatic Treatment in Bleeding Patients: A Systematic Review with Meta-Analysis and Trial Sequential Analysis. Anaesthesia, 72, 519-531. https://doi.org/10.1111/anae.13765

[7] Zaky, A. (2017) Thromboelastometry versus Rotational Thromboelastography in Cardiac Surgery. Seminars in Cardiothoracic and Vascular Anesthesia, 21, 206-211. https://doi.org/10.1177/1089253217697146

[8] Bochsen, L., Nielsen, A.B., Steinbruchel, D.A. and Johansson, P.I. (2007) Higher Thrombelastograph Platelet Reactivity in Cardiac Surgery Patients than in Blood Donors. Scandinavian Cardiovascular Journal, 41, 321-324.

https://doi.org/10.1080/14017430701225923

[9] Dai, Y., Lee, A., Critchley, L.A. and White, P.F. (2009) Does Thromboelastography Predict Postoperative Thromboembolic Events? A Systematic Review of the Literature. Anesthesia \& Analgesia, 108, 734-742. https://doi.org/10.1213/ane.0b013e31818f8907

[10] Kashuk, J.L., Moore, E.E., Sabel, A., Barnett, C., Haenel, J., Le, T., et al. (2009) Rapid Thrombelastography (r-TEG) Identifies Hypercoagulability and Predicts Thromboembolic Events in Surgical Patients. Surgery, 146, 764-772. https://doi.org/10.1016/j.surg.2009.06.054

[11] Zacho, M., Rafiq, S., Kelbaek, H., Johansson, P.I., Nielsen, M.B., Steinbruchel, D.A., et al. (2013) Hypercoagulability in Relation to Coronary Artery Bypass Graft Patency and Clinical Outcome. Scandinavian Cardiovascular Journal, 47, 104-108. https://doi.org/10.3109/14017431.2012.754934

[12] Chen, A. and Teruya, J. (2009) Global Hemostasis Testing Thromboelastography: Old Technology, New Applications. Clinics in Laboratory Medicine, 29, 391-407. https://doi.org/10.1016/j.cll.2009.04.003

[13] Pekelharing, J., Furck, A., Banya, W., Macrae, D. and Davidson, S.J. (2014) Comparison between Thromboelastography and Conventional Coagulation Tests after Cardiopulmonary Bypass Surgery in the Paediatric Intensive Care Unit. International Journal of Laboratory Hematology, 36, 465-471. https://doi.org/10.1111/ijlh.12171

[14] Lang, T. and von Depka, M. (2006) Possibilities and Limitations of Thrombelastometry/-Graphy. Hamostaseologie, 26, S20-S29.

https://doi.org/10.1055/s-0037-1617078

[15] Tannock, L. (2000) Dyslipidemia in Chronic Kidney Disease. In: Feingold, K.R., Anawalt, B., Boyce, A., Chrousos, G., Dungan, K., Grossman, A., et al., Eds., Endotext, MDText.com Inc., South Dartmouth, 3.

[16] Rac-Albu, M., Iliuta, L., Guberna, S.M. and Sinescu, C. (2014) The Role of Ankle-Brachial Index for Predicting Peripheral Arterial Disease. Maedica (Buchar), 9, 295-302.

[17] Rafiq, S., Johansson, P.I., Ostrowski, S.R., Stissing, T. and Steinbruchel, D.A. (2012) Hypercoagulability in Patients Undergoing Coronary Artery Bypass Grafting: Pre- 
valence, Patient Characteristics and Postoperative Outcome. European Journal of Cardio-Thoracic Surgery, 41, 550-555. https://doi.org/10.1093/ejcts/ezr001

[18] Tantry, U.S., Bliden, K.P., Suarez, T.A., Kreutz, R.P., Dichiara, J. and Gurbel, P.A. (2010) Hypercoagulability, Platelet Function, Inflammation and Coronary Artery Disease Acuity: Results of the Thrombotic Risk Progression (TRIP) Study. Platelets, 21, 360-367. https://doi.org/10.3109/09537100903548903

[19] Roeloffzen, W.W., Kluin-Nelemans, H.C., Mulder, A.B., Veeger, N.J., Bosman, L. and de Wolf, J.T. (2010) In Normal Controls, Both Age and Gender Affect Coagulability as Measured by Thrombelastography. Anesthesia \& Analgesia, 110, 987-994. https://doi.org/10.1213/ANE.0b013e3181d31e91

[20] Schreiber, M.A., Differding, J., Thorborg, P., Mayberry, J.C. and Mullins, R.J. (2005) Hypercoagulability Is Most Prevalent Early after Injury and in Female Patients. The Journal of Trauma, 58, 475-480. https://doi.org/10.1097/01.TA.0000153938.77777.26

[21] Theusinger, O.M., Nurnberg, J., Asmis, L.M., Seifert, B. and Spahn, D.R. (2010) Rotation Thromboelastometry (ROTEM) Stability and Reproducibility over Time. European Journal of Cardio- Thoracic Surgery, 37, 677-683. https://doi.org/10.1016/j.ejcts.2009.07.038

[22] Kon, Z.N., Kwon, M.H., Collins, M.J., Kallam, S., Sangrampurkar, R., Ozeki, T., et al. (2006) Off-Pump Coronary Artery Bypass Leads to a Regional Hypercoagulable State Not Detectable Using Systemic Markers. Innovations (Phila), 1, 232-238. https://doi.org/10.1097/01.imi.0000242160.21278.b7

[23] Manchio, J.V., Gu, J., Romar, L., Brown, J., Gammie, J., Pierson, R.N., et al. (2005) Disruption of Graft Endothelium Correlates with Early Failure after Off-Pump Coronary Artery Bypass Surgery. The Annals of Thoracic Surgery, 79, 1991-1998. https://doi.org/10.1016/j.athoracsur.2004.12.054

[24] Rafiq, S., Johansson, P.I., Zacho, M., Stissing, T., Kofoed, K., Lilleor, N.B., et al. (2012) Thrombelastographic Haemostatic Status and Antiplatelet Therapy after Coronary Artery Bypass Surgery: TEG-CABG Trial, Assessing and Monitoring the Antithrombotic Effect of Clopidogrel and Aspirin versus Aspirin Alone in Hypercoagulable Patients: Study Protocol for a Randomized Controlled Trial. Trials, 13, 48. https://doi.org/10.1186/1745-6215-13-48

[25] Huynh, T., Theroux, P., Bogaty, P., Nasmith, J. and Solymoss, S. (2001) Aspirin, Warfarin, or the Combination for Secondary Prevention of Coronary Events in $\mathrm{Pa}$ tients with Acute Coronary Syndromes and Prior Coronary Artery Bypass Surgery. Circulation, 103, 3069-3074. https://doi.org/10.1161/01.CIR.103.25.3069

[26] Kulik, A., Ruel, M., Jneid, H., Ferguson, T.B., Hiratzka, L.F., Ikonomidis, J.S., et al. (2015) Secondary Prevention after Coronary Artery Bypass Graft Surgery: A Scientific Statement from the American Heart Association. Circulation, 131, 927-964. https://doi.org/10.1161/CIR.0000000000000182

[27] Henderson, W.G., Goldman, S., Copeland, J.G., Moritz, T.E. and Harker, L.A. (1989) Antiplatelet or Anticoagulant Therapy after Coronary Artery Bypass Surgery. A Meta-Analysis of Clinical Trials. Annals of Internal Medicine, 111, 743-750. https://doi.org/10.7326/0003-4819-111-9-743

[28] Taggart, D.P., Boyle, R., de Belder, M.A. and Fox, K.A. (2011) The 2010 ESC/EACTS Guidelines on Myocardial Revascularisation. Heart, 97, 445-446.

https://doi.org/10.1136/hrt.2010.216135 